\title{
Neuromuscular Synapse Formation in Mice Lacking Motor Neuron- and Skeletal Muscle-Derived Neuregulin-1
}

\author{
Alexander Jaworski and Steven J. Burden \\ Molecular Neurobiology Program, Skirball Institute of Biomolecular Medicine, New York University School of Medicine, New York, New York 10016
}

The localization of acetylcholine receptors (AChRs) to the vertebrate neuromuscular junction is mediated, in part, through selective transcription of $A C h R$ subunit genes in myofiber subsynaptic nuclei. Agrin and the muscle-specific receptor tyrosine kinase, MuSK, have critical roles in synapse-specific transcription, because $A C h R$ genes are expressed uniformly in mice lacking either agrin or MuSK. Several lines of evidence suggest that agrin and MuSK stimulate synapse-specific transcription indirectly by regulating the distribution of other cell surface ligands, which stimulate a pathway for synapse-specific gene expression. This putative secondary signal for directing $A C h R$ gene expression to synapses is not known, but Neuregulin-1 (Nrg-1), primarily based on its presence at synapses and its ability to induce AChR gene expression in vitro, has been considered a good candidate. To study the role of Nrg-1 at neuromuscular synapses, we inactivated $n r g-1$ in motor neurons, skeletal muscle, or both cell types, using mice that express Cre recombinase selectively in developing motor neurons or in developing skeletal myofibers. We find that AChRs are clustered at synapses and that synapse-specific transcription is normal in mice lacking Nrg-1 in motor neurons, myofibers, or both cell types. These data indicate that Nrg-1 is dispensable for clustering AChRs and activating $A C h R$ genes in subsynaptic nuclei during development and suggest that these aspects of postsynaptic differentiation are dependent on Agrin/MuSK signaling without a requirement for a secondary signal.

Key words: ErbB; Cre recombinase; Z/AP reporter mice; tyrosine kinase; acetylcholine receptor; synaptogenesis

\section{Introduction}

A hallmark of neuromuscular synapse formation is the localization of multiple proteins, including acetylcholine receptors (AChRs), the muscle-specific receptor tyrosine kinase, MuSK, neuregulin-1 (Nrg-1), and ErbBs to the postsynaptic myofiber membrane. Additionally, the genes encoding AChR subunits and MuSK are selectively transcribed in subsynaptic myofiber nuclei (Sanes and Lichtman, 2001; Burden, 2002).

The clustering of synaptic proteins is dependent on MuSK. MuSK is activated by motor neuron-derived agrin (Glass et al., 1996), and mice lacking Agrin or MuSK lack neuromuscular synapses, because postsynaptic proteins fail to cluster and genes that are normally expressed preferentially in the synaptic region of muscle are expressed uniformly in myofibers (DeChiara et al., 1996; Gautam et al., 1996). MuSK is also sufficient for clustering synaptic proteins and inducing "synaptic genes," because ectopic expression of Agrin or constitutively active MuSK stimulates AChR clustering and AChR transcription (Cohen et al., 1997; Jones et al., 1997, 1999; Moore et al., 2001; Lacazette et al., 2003).

$\mathrm{Nrg}-1$, a ligand for ErbBs, has been implicated in regulating synapse-specific transcription, because Nrg-1 stimulates expres-

Received Sept. 9, 2005; revised Nov. 21, 2005; accepted Nov. 23, 2005.

This work was supported by grants from the National Institutes of Health to S.J.B. We thank Judith Melki and Kevin Campbell for HSA:: cre mice; Christopher William, Silvia Arber, and Tom Jessell for $I / 1^{\text {cre }}$ mice; Carmen Birchmeier for $n r g-1^{+/-}$and $n r g-1^{f /+}$ mice; lihua Fan for expert technical assistance; and Moses Chao and Matthew Friese for thoughtful comments on this manuscript.

Correspondence should be addressed to Steven J. Burden, Molecular Neurobiology Program, New York University Medical Center, 540 First Avenue, New York, NY 10016. E-mail: burden@saturn.med.nyu.edu.

DOI:10.1523/JNEUROSCI.4506-05.2006

Copyright $\odot 2006$ Society for Neuroscience $\quad$ 0270-6474/06/260655-07\$15.00/0 sion of certain genes, including AChR genes, in cultured muscle cells (Falls et al., 1993; Chu et al., 1995; Gramolini et al., 1999; Ip et al., 2000). Moreover, Nrg-1 and ErbBs are concentrated at synapses (Goodearl et al., 1995; Jo et al., 1995; Moscoso et al., 1995; Zhu et al., 1995), and the response of AChR genes to Nrg-1 in vitro and synapse-specific transcription in vivo depend on the same cis-regulatory elements (Gundersen et al., 1993; Tang et al., 1994; Fromm and Burden, 1998; Schaeffer et al., 1998). Nrg-1 is expressed by motor neurons, suggesting that Nrg-1 may regulate muscle differentiation in a paracrine manner (Sandrock et al., 1995). Nrg-1, however, is also expressed by muscle (Corfas et al., 1995; Rimer et al., 1998). Moreover, muscle-derived Nrg-1 and ErbBs are clustered by Agrin, raising the possibility that Nrg-1 may act in an autocrine manner, downstream of MuSK, to regulate synaptic differentiation (Meier et al., 1998; Rimer et al., 1998; Moore et al., 2001; Lacazette et al., 2003).

Analysis of the potential role for Nrg-1 in synapse-specific transcription is complicated by its requirement in other developmental processes that precede synapse formation and by the presence of multiple Nrg-1 receptors at synapses (Gassmann et al., 1995; Lee et al., 1995; Meyer and Birchmeier, 1995; Riethmacher et al., 1997; Morris et al., 1999; Woldeyesus et al., 1999). Conditional inactivation of Nrg-1 in sensory and motor neurons, which leads to a loss of Schwann cells and a subsequent loss of motor axons from muscle, does not affect the pattern of $A C h R$ gene expression, implying that neuronal $\mathrm{Nrg}-1$ is dispensable for synapse-specific transcription (Yang et al., 2001). These results, however, do not exclude the possibility that neuronal Nrg-1 regulates the level of AChR expression or that muscle-derived Nrg-1 is critical for synapse-specific transcription. Here, we condition- 
ally inactivate $n r g-1$ in skeletal muscle, motor neurons, or both cell types and quantitatively assess AChR expression. We find that Nrg- 1 is dispensable for synapse-specific transcription and clustering of synaptic AChRs during development.

\section{Materials and Methods}

Mouse strains and genotyping. Isl ${ }^{c r e}$ mice have been described previously (Srinivas et al., 2001). Mice were genotyped by PCR using a primer within the neomycin cassette (TGGCTACCCGTGATATTGCT) and a primer within the isl locus (GGCTCTCTCCACCACATCGT). Human skeletal actin (HSA)::cre mice have been described previously (Miniou et al., 1999); mice were genotyped by PCR using a primer in the HSA promoter (AAGTGAAGCCTCGCTTCC) and a primer in the cre coding region (CCTCATCACTCGTTGCATCGA). Z/AP mice, carrying a floxed lac $Z$ expression cassette, have been characterized previously (Lobe et al., 1999); the mice were genotyped by PCR using a pair of primers in the hPLAP coding sequence (CCGCTTCCCATATGTGGCTCTGTCC and GCATGA GCTCAGTGCGGTTCCACAC). The $n r g-1$ null allele, lacking exons 7, 8, and 9, has been described previously (Meyer and Birchmeier, 1995). Because exons 7 and 8 encode the epidermal growth factor-like domain, which is required to activate ErbB receptors, the mutant allele is a null. In $n r g-1^{f}$ mice, exons 7,8 , and 9 are flanked by loxP sites, allowing conditional inactivation of $n r g-1$ (Yang et al., 2001). LoxP-flanked and wild-type alleles were detected using primers in $n r g-1$ (GAGATGGTCATGTCCTTGTCACTAAC and GCACCAAGTGGTTGCGATTGTTGCT); the null allele was detected using a primer in $n r g-1$ (GAGATGGTCATGTCCTTGTCACTAAC) and a primer in the neomycin cassette (CGAATTCGCCAATGACAAGACGCTG).

Histology and measurement of $\beta$-galactosidase activity. Cryostat cross sections $(10 \mu \mathrm{m})$ from hindlimbs, diaphragm, and intercostal muscles [embryonic day 18.5 (E18.5)] were fixed for $10 \mathrm{~min}$ in PBS containing $2 \%$ formaldehyde, $0.2 \%$ glutaraldehyde, $50 \mathrm{~mm}$ EGTA, and $100 \mathrm{~mm}$ magnesium chloride and washed twice with buffer A (PBS containing $2 \mathrm{~mm}$ magnesium chloride, $0.02 \%$ Nonidet P- 40 , and $0.01 \%$ sodium deoxycholate) for $5 \mathrm{~min}$ at room temperature. Sections were stained for $\beta$-galactosidase ( $\beta$-gal) activity with $0.5 \mathrm{mg} / \mathrm{ml} 5$-bromo-4-chloro-3indolyl- $\beta$ D-galactoside (X-gal), 5 mм potassium ferrocyanide, $5 \mathrm{~mm}$ potassium ferricyanide, and $1.25 \%$ dimethylformamide in buffer $\mathrm{A}$ at $37^{\circ} \mathrm{C}$ in the dark. The staining reaction was allowed to proceed for $0.25,0.5,1$, 4 , or $10 \mathrm{~h}$. Sections were washed twice for $5 \mathrm{~min}$ with buffer $\mathrm{A}$ at room temperature and mounted under GelMount (Biomeda, Foster City, CA).

Images, which were captured on a Sony (Tokyo, Japan) DKC500 camera, were analyzed with NIH ImageJ. Grayscale values for 40 muscle fibers in each muscle were determined at each time point. Because mean grayscale values of unstained sections and stained sections from wildtype mice were identical, these values were averaged and used as a baseline for measuring product accumulation in Z/AP and HSA::cre; Z/AP mice. $\beta$-Gal activity in skin and bone from $Z / A P$ mice and HSA::cre; $Z / A P$ mice were indistinguishable (data not shown), indicating that $H S A:: c r e$ is not detectably expressed in skin and bone. For each animal, we plotted the average grayscale value in myofibers over time. For $Z / A P$ mice, we plotted product accumulation during the first hour; for $H S A:: c r e ; Z / A P$ mice, we plotted product accumulation during the entire $10 \mathrm{~h}$ reaction period. The slopes were generated by linear regression $\left(R^{2}\right.$ values for the slopes were larger than 0.9) and were used to compare enzyme activity.

Immunohistochemistry. Diaphragm and gastrocnemius muscles were fixed for $1 \mathrm{~h}$ at room temperature (1\% formaldehyde in PBS) and then overnight at $4^{\circ} \mathrm{C}(0.2 \%$ formaldehyde in PBS). Unless indicated otherwise, all incubations were performed at room temperature. Gastrocnemius muscles were teased into bundles of muscle fibers. Muscles were washed twice for $15 \mathrm{~min}$ in PBS, incubated $15 \mathrm{~min}$ with $100 \mathrm{~mm}$ glycine in PBS, and rinsed in PBS. After removal of the overlying connective tissue, muscles were permeabilized and blocked for $1 \mathrm{~h}$ in PBS containing 2\% bovine serum albumin, $4 \%$ normal goat serum, and $0.5 \%$ Triton X-100.

To label axons, AChRs, and muscle fibers, muscles were incubated at $4^{\circ} \mathrm{C}$ overnight with rabbit polyclonal antibodies against neurofilament (1:500; Chemicon, Temecula, CA) and synaptophysin (1:5; Zymed, San Francisco, CA) in blocking solution. After three washes ( $1 \mathrm{~h}$ per wash) in
PBS containing 0.5\% Triton X-100 (PBT), muscles were incubated for $2 \mathrm{~h}$ with fluorescein-conjugated donkey anti-rabbit IgG (1:200; Jackson ImmunoResearch, West Grove, PA), Alexa594-conjugated $\alpha$-bungaratoxin ( $\alpha$-Bgt; 1:1000; Invitrogen, San Diego, CA), and Alexa660-conjugated phalloidin (1:100; Invitrogen) in blocking solution.

To quantitate the number and density of AChRs, muscles were stained only with Alexa594- $\alpha$-Bgt, first for $1 \mathrm{~h}$ at room temperature and then overnight at $4^{\circ} \mathrm{C}$. After three 30 min washes in PBT, muscles were rinsed in PBS, fixed 30 min with $1 \%$ formaldehyde in PBS, washed three times for 10 min in PBS, and flat-mounted in Vectashield (Vector Laboratories, Burlingame, CA). Images were captured using a Zeiss (Oberkochen, Germany) LSM 510 confocal microscope.

Quantitation of synaptic AChRs. To compare AChR levels and density between wild-type and $n r g-1$ mutant endplates, confocal image stacks of Alexa594- $\alpha$-Bgt-stained muscles were captured at a subsaturating amplifier gain, which was not modified during the course of the experiment. Moreover, we confirmed the validity of this assay by including increasing amounts of unlabeled $\alpha$-Bgt, together with Alexa594- $\alpha$-Bgt, and showing that the fluorescence intensity was reduced in a linear manner (data not shown). The data were quantitated using Volocity 3D software (Improvision, Lexington, MA). For each AChR cluster, we determined the average fluorescence intensity per cubic micrometer and the summed fluorescence intensity of all voxels associated with the cluster. We analyzed at least 77 synapses in each E18.5 embryo and $>20$ synapses in each postnatal day 21 (P21) mouse. Mean AChR density from multiple mice ( $n$ is indicated in the figure legends) with the same genotype was determined. We used a two-tailed $t$ test to determine whether differences in AChR density were statistically significant. Because AChR densities in P21 nrg- $1^{f /-}$ and $n r g-1^{f /+}$ mice were not significantly different (data not shown), these genotypes were grouped.

In situ hybridization. Intercostal muscles were fixed in $4 \%$ formaldehyde, dehydrated in methanol, digested with proteinase $\mathrm{K}$, hybridized with digoxigenin-labeled riboprobes directed against mRNAs encoding $A C h R \alpha$ subunit (DeChiara et al., 1996), $A C h R \delta$ subunit (Simon et al., 1992), AChR $\epsilon$ subunit (nucleotides 165-1485 from start codon; GenBank accession number NM_009603), MuSK (Herbst et al., 2002), or Utrophin (Utrn) (nucleotides 119-865 from start codon; GenBank accession number NM_011682), and processed as described previously (Wilkinson, 1998; Yang et al., 2001). Labeling with sense probes resulted in weak, uniform staining for each gene (data not shown).

Quantitative reverse transcription-PCR. Gastrocnemius muscles were homogenized at $4^{\circ} \mathrm{C}$ in RNA STAT-60 (Tel-Test, Friendswood, TX) using a PT 10/35 Polytron (Kinematica AG, Littau-Lucerne, Switzerland), and RNA was isolated according to the manufacturer's recommendations. After treatment with DNase I, RNA was reverse transcribed using the iScript cDNA synthesis kit (Bio-Rad, Hercules, CA). Five percent of each reverse transcription (RT) reaction was used for quantitative PCR using iQ SYBR Green Supermix (Bio-Rad) on an Opticon 2 real-time thermocycler (Bio-Rad). Relative expression levels of AChR $\delta$ subunit and MuSK were normalized to glyceraldehyde-3-phosphate dehydrogenase (gapdh) expression. The linearity of quantitative PCRs was confirmed by analyzing serial dilutions of samples, and each reaction was performed in duplicate. The primers used for PCR amplification were TGCATCCTGCACCACCAACT and ATGCCTGCTTCACCACCTTC for $g a p d h$, CCCTGCAAGTGAAGATGAAA and TTCAAGAACTGCGATTCTGG for $M u S K$, and CATCGAGTGGATCATCATTGAC and CGGCGGATGATAAGGTAGAA for $A C h R \delta$. Primer pairs were located in different exons to avoid amplification from contaminating genomic DNA.

\section{Results \\ Neuronal neuregulin-1 is not required to cluster synaptic AChRs}

Previously, we showed that the pattern of $A C h R$ gene expression is normal in embryos lacking neuronal Nrg-1 (Yang et al., 2001). Because our studies did not provide quantitative data on $A C h R$ RNA or protein expression, it remained possible that AChRs were clustered at a reduced density at neuromuscular synapses in neuronal $n r g-1$ mutant mice. We therefore inactivated neuronal 

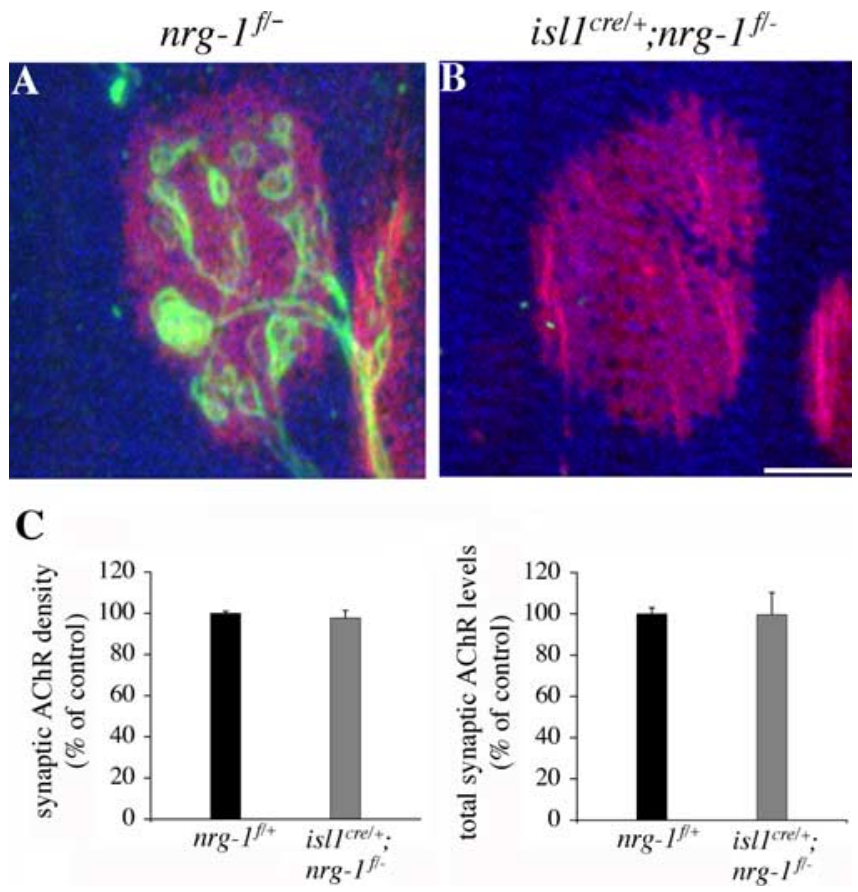

Figure 1. Neuronal Nrg-1 is dispensable for normal clustering of AChRs at synapses. Whole mounts of diaphragm muscles from E18.5 neuronal $n r g-1$ mutant embryos $(\boldsymbol{B})$ and control littermates $(\boldsymbol{A})$ were stained with Alexa594 - $\alpha$-bungaratoxin to visualize postsynaptic AChRs (red), antibodies against neurofilament and synaptophysin to visualize motor axons and nerve terminals (green), respectively, and Alexa660 - phalloidin to visualize muscle fibers (blue). $A$, In control mice, postsynaptic AChR clusters are apposed to nerve terminals. $\boldsymbol{B}$, In mice lacking neuronal $\mathrm{Nrg}$-1, motor axons have withdrawn, but AChRs remain clustered at synaptic sites, and AChR clusters are of similar size and shape as AChR clusters in control mice. Scale bar: (in $\boldsymbol{B}) \boldsymbol{A}, \boldsymbol{B}$, $5 \mu \mathrm{m}$. C, Synaptic AChR density and total synaptic AChR levels are indistinguishable in neuronal $n r g-1$ mutant mice $(n=4)$ and control littermates $(n=5)$. Error bars indicate SEM.

Nrg-1 by crossing $n r g-1$ mutant mice with isl ${ }^{\text {cre }}$ mice, which express Cre recombinase in sensory and motor neurons (Srinivas et al., 2001). We labeled AChRs in diaphragm muscle from E18.5 isl $1^{\text {cre/+ }}$; $n r g-1^{f /-}$ embryos and control littermates with Alexa$594-\alpha$-Bgt and quantitated the density of AChRs at synaptic sites (Fig. 1) (see Materials and Methods). We found no significant difference in the density or total number of AChRs at synaptic sites in control mice and mice lacking neuronal Nrg-1 (density, $98 \pm 3.6 \%$ of control, $p>0.5$; total levels, $100 \pm 10.7 \%$ of control, $p>0.5$ ) (Fig. $1 C$ ). Similar results were obtained for gastrocnemius muscle (density, $108 \pm 6.5 \%$ of control, $p>0.5$; total levels, $106 \pm 8.1 \%$ of control, $p>0.5 ; n=3$ for control; $n=$ 2 for mutant). These data demonstrate that neuronal Nrg-1 is not only dispensable for selectively expressing $A C h R$ genes in the synaptic region of muscle but also for expressing $A C h R$ protein at normal density at synaptic sites.

\section{Quantitation of Cre-mediated deletion of loxP-flanked sequences in muscle}

Previous studies have shown that Nrg-1 is expressed by skeletal muscle as well as by motor neurons. Thus, we considered the possibility that muscle-derived, rather than neuronal, Nrg-1 is necessary to express $A C h R$ genes selectively in the synaptic region of muscle and to cluster AChRs at synaptic sites. To inactivate muscle-derived Nrg-1, we generated mice carrying a HSA::cre transgene and null and loxP-flanked alleles of $n r g-1$ (HSA::cre; $\left.n r g-1^{f /-}\right)$. HSA::cre mice express Cre recombinase selectively in somites as early as E9.5, and by P0, Cre-mediated inactivation of
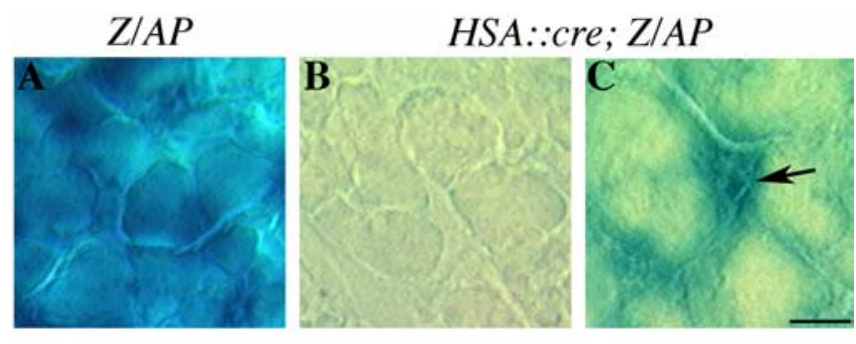

D

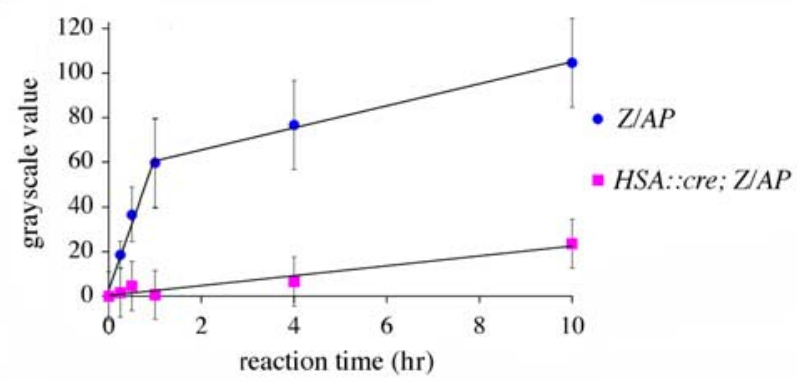

E

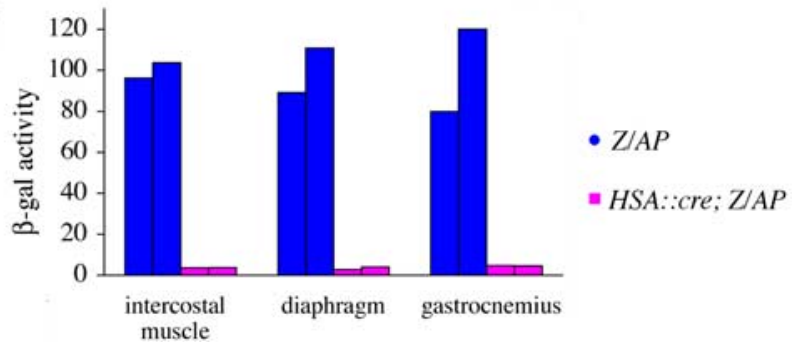

Figure 2. Efficient Cre-mediated deletion of loxP-flanked target genes in skeletal muscle of HSA.:cre mice. Cross sections of gastrocnemius, diaphragm, and intercostal muscles from Z/AP and $H S A$ ::cre; Z/AP mice were stained to visualize and measure $\beta$-gal activity. The reaction was terminated at different time points, and grayscale values from muscle fibers were analyzed to measure product accumulation and determine $\beta$-gal activity (see Materials and Methods). $\boldsymbol{A}, \boldsymbol{B}$, Representative images of intercostal muscles stained for $1 \mathrm{~h}$. C, After a $10 \mathrm{~h}$ reaction, interstitial cells, located between myofibers, are intensely stained (arrow), and diffusion of this stain is likely to contribute to product accumulation in adjacent myofibers. Scale bar: (in C) $A, B, 10 \mu \mathrm{m}$; $C, 8 \mu \mathrm{m}$. D, Plotted grayscale values (with SDs) for intercostal muscles from a single $Z / A P$ and a single HSA::cre; Z/AP mouse. $E, \beta$-gal activity in muscle of two Z/AP mice (the average of the 2 mice was assigned a value of $100 \%$ ) and two HSA.:.cre; Z/AP mice. The HSA::cre transgene reduces $\beta$-gal activity ( $>95 \%)$ in all muscle groups.

loxP-flanked alleles in skeletal muscle has been described as efficient and uniform among muscles (Miniou et al., 1999). To quantitate how effectively loxP-flanked sequences are deleted in skeletal muscle of HSA::cre mice, we crossed HSA::cre mice with $Z / A P$ reporter mice (Lobe et al., 1999). Because $Z / A P$ reporter mice contain a lac $Z$ cassette that is flanked by loxP sites, Cremediated recombination deletes lac $Z$, inactivating $\beta$-gal expression. We visualized $\beta$-gal expression by staining sections of muscle with $\mathrm{X}$-gal. In $Z / A P$ mice, $\beta$-gal is expressed in multiple cell types within skeletal muscle, including myofibers (Fig. $2 A$ ). In muscles from HSA::cre; Z/AP mice, stained for $1 \mathrm{~h}, \beta$-gal staining is essentially absent from myofibers (Fig. $2 \mathrm{~B}$ ); after a $10 \mathrm{~h}$ reaction, interstitial cells are intensely stained (Fig. $2 C$ ), and diffusion of this stain may contribute to product accumulation in myofibers at later time points.

We quantitated $\beta$-gal expression in Z/AP and HSA::cre; Z/AP mice by staining cross-sections of muscle from E18.5 embryos with $\mathrm{X}$-gal and measuring the rate of product accumulation over time (Fig. $2 D$ ). We defined the average $\beta$-gal activity in myofibers from $Z / A P$ mice as $100 \%$ and found that $\beta$-gal activity in HSA::cre; Z/AP mice was reduced by $95 \%$ in gastrocnemius mus- 

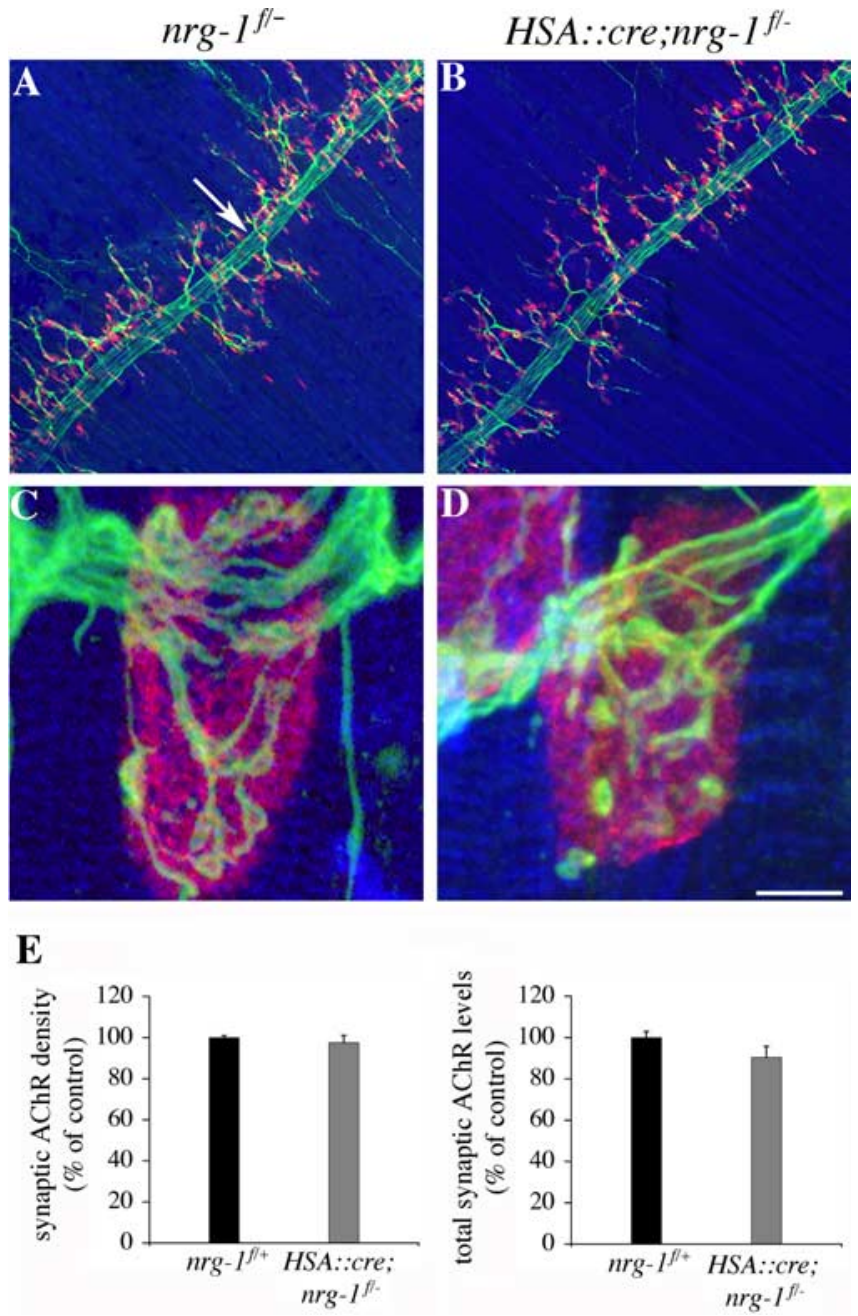

Figure 3. Muscle-derived Nrg-1 is not required for motor innervation and clustering AChRs at synapses. Whole mounts of diaphragm muscles from E18.5 embryos lacking muscle-derived $\operatorname{Nrg}-1(\boldsymbol{B}, \boldsymbol{D})$ and control littermates $(\boldsymbol{A}, \boldsymbol{C})$ were stained as described in Figure 1. $\boldsymbol{A}-\boldsymbol{D}$, In control mice and mice lacking muscle-derived $\mathrm{Nrg}$-1, the main intramuscular nerve is positioned in the central region of the diaphragm muscle (arrow in $\boldsymbol{A}$ ), and individual motor axon branches innervate muscle fibers adjacent to the main nerve trunk. $\boldsymbol{C}, \boldsymbol{D}$, Nerve terminals are apposed to AChR clusters of normal appearance. Scale bar: (in $\boldsymbol{D}) \boldsymbol{A}, \boldsymbol{B}, 125 \mu \mathrm{m} ; \boldsymbol{C}, \boldsymbol{D}, 5 \mu \mathrm{m}$. $\boldsymbol{E}$, Synaptic AChR density and total synaptic AChR levels in $n r g-1$ mutant mice $(n=5)$ and control littermates $(n=5)$ are not significantly different. Error bars indicate SEM.

cles (95.2 and $95.4 \%$ in two animals), 97\% in diaphragm (97.2 and $96.0 \%$ in two animals), and $96 \%$ in intercostal muscles (96.4 and $96.3 \%$ in two animals) (Fig. 2E). Thus, the HSA::cre transgene efficiently deletes loxP-flanked sequences in skeletal muscle.

Muscle-derived neuregulin-1 is not required to cluster AChRs at synaptic sites during embryogenesis

To inactivate muscle-derived Nrg-1, we generated HSA:: cre; $n r g-$ $1^{f /-}$ mice. At E18.5, $1 \mathrm{~d}$ before birth, HSA::cre; $n r g-1^{f /-}$ embryos were recovered at the expected Mendelian frequency. To study presynaptic and postsynaptic differentiation, we stained whole mounts of diaphragm muscle with probes that allowed us to visualize motor axons, nerve terminals, muscle fibers, and AChRs (see Materials and Methods). In $n r g-1^{f /-}$ embryos, like in wildtype embryos, the main intramuscular nerve is located in the central region of the diaphragm and oriented perpendicular to the muscle fibers (Fig. 3A); nerve terminals innervate muscle fibers adjacent to the main nerve trunk, and AChRs are concen- trated at these synaptic contacts (Fig. $3 A, C$ ). In E18.5 HSA::cre; $n r g-1^{f /-}$ embryos, the main intramuscular nerve is properly positioned, and motor axons innervate muscle fibers of normal arrangement, size, and structure (Fig. $3 B, D$ ). Moreover, the distribution, size, and shape of synaptic AChR clusters appear normal (Fig. 3). These findings indicate that expression of Nrg-1 in skeletal muscle is not essential for the development of muscle fibers, growth of motor axons to muscle, or formation of synapses.

Because these findings do not provide quantitative data on the level of AChR protein expression, we could not exclude the possibility that Nrg-1 is required to cluster AChRs at their normal density at neuromuscular synapses. Therefore, we measured synaptic AChR protein expression by quantitating the amount of Alexa594- $\alpha$-Bgt bound to synaptic AChRs in diaphragm muscle (Fig. $3 E$ ). We found no significant difference in the density or total number of AChRs at synapses in HSA::cre; $n r g-1^{f /-}$ and control mice (density, $98 \pm 3.6 \%$ of control, $p>0.5$; total levels, $90 \pm 5.4 \%$ of control, $p>0.1$ ) (Fig. $3 E$ ) [ similar results were obtained for gastrocnemius muscle (density, $103 \pm 7.1 \%$ of control, $p>0.5$; total levels, $94 \pm 3.6 \%$ of control, $p>0.2 ; n=3$ for control; $n=5$ for mutant)], indicating that expression of synaptic AChRs does not depend on muscle-derived Nrg-1.

Muscle-derived neuregulin-1 is not required for postsynaptic differentiation in postnatal mice

Neuronal Nrg-1 is required for survival of Schwann cells. In the absence of Schwann cells, motor neurons are generated, extend axons to muscle, and form neuromuscular synapses, but these motor neurons die shortly before birth. Thus, in the absence of neuronal Nrg-1, mice lack innervation and die at birth (Yang et al., 2001). Mice lacking muscle-derived Nrg-1, however, are born at the expected Mendelian frequency and are indistinguishable from control mice in size and weight (at P21; nrg- 1 mutant, $5.19 \pm 0.12 \mathrm{~g}, n=4$; control, $5.55 \pm 0.46 \mathrm{~g}, n=3$ ). To determine whether muscle-derived Nrg-1 regulates maturation or maintenance of neuromuscular synapses postnatally, we visualized motor neurons, muscle fibers, and AChRs in whole mounts of diaphragm muscles from P21 $n r g-1^{f /-}$ and HSA::cre; $n r g-1^{f /-}$ mice. We found that the size and shape of synaptic AChR clusters are similar in HSA::cre; $n r g-1^{f /-}$ and $n r g-1^{f /-}$ control mice (Fig. $4 A, B)$. Likewise, the position of motor axons and the shape and size of nerve terminals appear normal in HSA:: $\mathrm{cre}$; $n \mathrm{rg}-1^{f /-}$ mice (Fig. $4 A, B$ ). Thus, in the absence of muscle-derived Nrg-1, neuromuscular synapses are morphologically indistinguishable from wild-type synapses.

To determine whether muscle-derived Nrg-1 is required to maintain AChR expression postnatally, we measured the density and number of synaptic AChRs in P21 mice lacking musclederived Nrg-1 and in control littermates. We found that synaptic AChR density and number are indistinguishable in control and mutant mice (density, $102 \pm 5.9 \%$ of control, $p>0.5$; total levels, $94 \pm 9.6 \%$ of control, $p>0.5$ ) (Fig. 4C). Thus, neuromuscular synapses develop and contain normal levels of AChRs independent of Nrg-1 expression from skeletal muscle fibers.

Because mice lacking muscle-derived Nrg-1 survive past birth, they provide an opportunity to study the potential role of $\mathrm{Nrg}-1$ in switching from the embryonic AChR $\gamma$ subunit to the adult AChR $\epsilon$ subunit. We examined the expression pattern of the AChR $\epsilon$-subunit gene in intercostal muscles of P21 HSA::cre; $n$ rg$1^{f /-}$ mice by in situ hybridization and found that $A C h R \epsilon$-subunit mRNA is concentrated in the central region of muscle from mutant mice, like control littermates (Fig. $4 D, E$ ). Similar results were obtained for diaphragm muscle (data not shown). These 

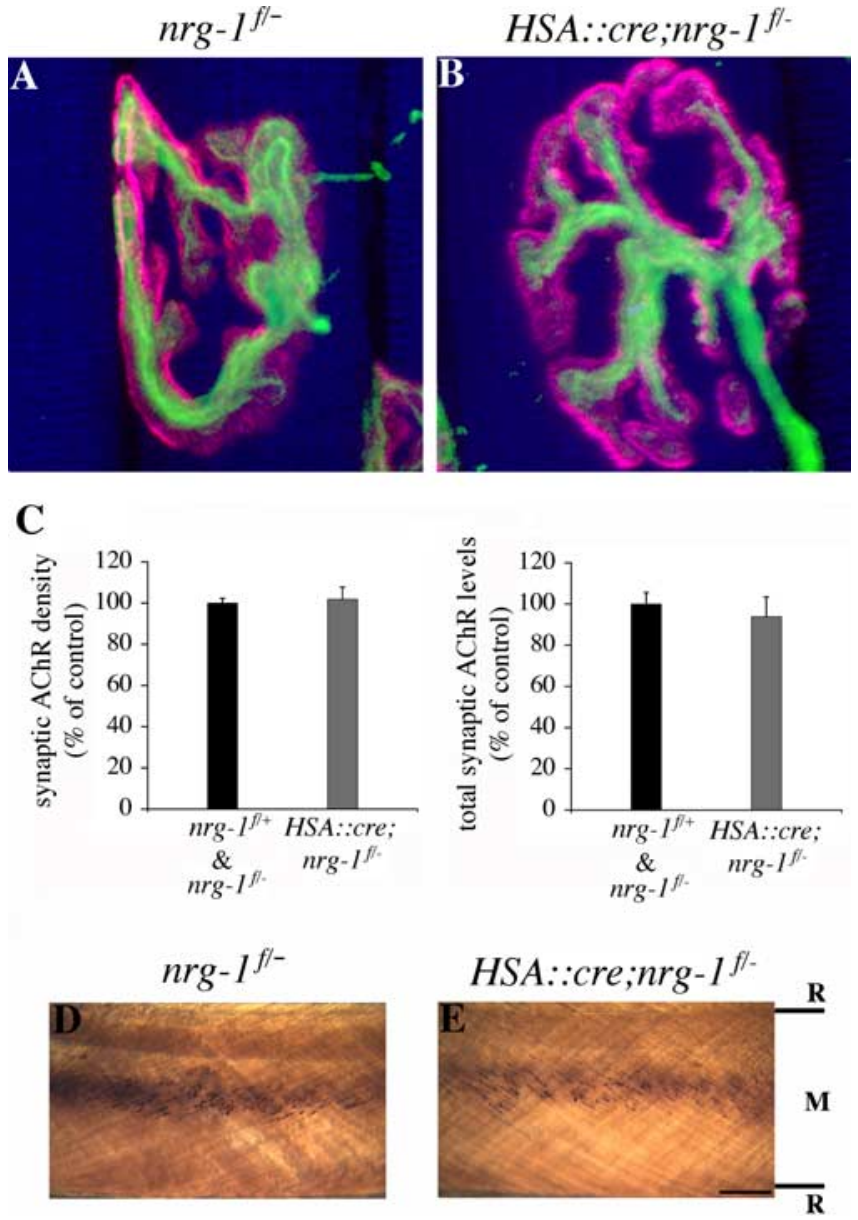

Figure 4. Synapses mature normally in the absence of muscle-derived Nrg-1. $A, B$, Whole mounts of diaphragm muscles from P21 control mice and mice lacking muscle-derived Nrg-1 were stained as described in Figure 1. By P21, the shape of the neuromuscular synapse has matured from a plaque-like to a pretzel-like structure in control mice and mice lacking musclederived Nrg-1. C, The density and total number of synaptic AChRs is similar in muscle from control mice $(n=3)$ and mice lacking muscle-derived Nrg-1 $(n=4)$. Error bars indicate SEM. $\boldsymbol{D}$, $\boldsymbol{E}$, Whole mounts of intercostal muscles from P21 control mice (D) and mice lacking musclederived $\operatorname{Nrg}-1(\boldsymbol{E})$ were processed for in situ hybridization. AChR $\in$ mRNA is concentrated in the central region of muscle from $n r g-1$ mutant P21 mice, similar to control mice. M indicates the position of the muscle, and $R$ indicates the location of the ribs. Scale bar: (in $\boldsymbol{E}) \boldsymbol{A}, \boldsymbol{B}, 10 \mu \mathrm{m} ; \boldsymbol{D}$, $E, 200 \mu \mathrm{m}$.

results indicate that muscle-derived Nrg-1 is dispensable for activating $A C h R \quad \epsilon$-subunit transcription in synaptic nuclei postnatally.

Synapse-specific transcription and postsynaptic differentiation in mice lacking both neuronal- and muscle-derived neuregulin-1

Postsynaptic differentiation is normal in mice lacking either neuronal- or muscle-derived Nrg-1. These findings raise the possibility that neuronal- and muscle-derived $\mathrm{Nrg}-1$ have redundant roles in neuromuscular synapse formation. We therefore generated mice carrying both isl1 ${ }^{\text {cre }}$ and HSA::cre genes and null and loxP-flanked alleles of $n r g-1$ and examined presynaptic and postsynaptic differentiation, including the pattern and level of $A C h R$ gene expression and the density of synaptic AChRs.

We examined the pattern of $A C h R$ gene expression in intercostal muscles of HSA:: $\mathrm{cre}$; isl1 ${ }^{\text {crel+}} ;$ nrg- $1^{f /-}$ E18.5 embryos by in situ hybridization and found that $A C h R \alpha$-subunit and $A C h R$ $\delta$-subunit mRNAs are patterned normally in muscle from the

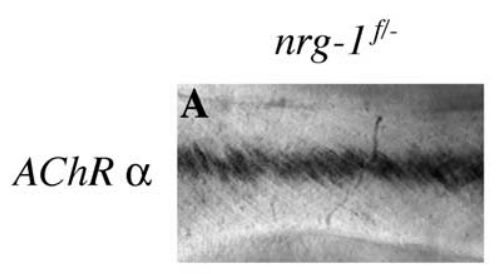

HSA::cre; isll crel+; $^{\text {; }}$ $n r g-1^{f /-}$

$\operatorname{AChR} \delta$
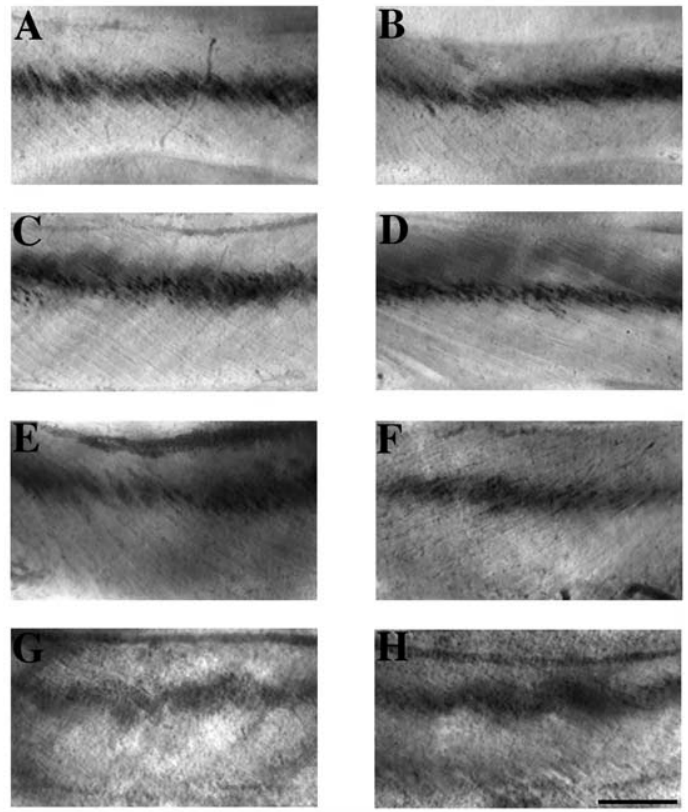

I

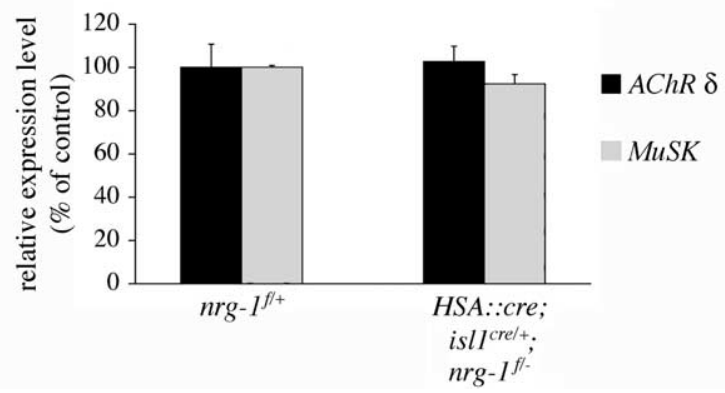

Figure 5. Synapse-specific gene expression is normal in mice lacking Nrg-1 in motor neurons and skeletal muscle. $\boldsymbol{A}-\boldsymbol{H}$, Whole mounts of intercostal muscles from E18.5 embryos lacking neuronal-and muscle-derived $\operatorname{Nrg}-1(A, C, E, G)$ and control $(B, D, F, H)$ mice were processed for in situ hybridization. $A C h R \alpha$ subunit $(\boldsymbol{A}, \boldsymbol{B}), A C h R \delta$ subunit $(\boldsymbol{C}, \boldsymbol{D}), \operatorname{MuSK}(\boldsymbol{E}, \boldsymbol{F})$, and $U \operatorname{trn}(\boldsymbol{G}, \boldsymbol{H})$ mRNAs are concentrated in the central region of muscle from mice lacking Nrg-1 in motor neurons and skeletal muscle, like in control mice. Scale bar (in $\boldsymbol{H}) \boldsymbol{A}-\boldsymbol{H}, 200 \mu \mathrm{m}$. I, RNA from gastrocnemius muscles of E18.5 embryos lacking neuronal and muscle-derived Nrg-1 and from control mice was reverse transcribed into $C D N A$, and gene expression were measured by realtime PCR. The expression levels of $A C h R \delta$ and MuSK are similar in mice lacking Nrg- 1 in motor neurons and muscle $(n=3)$ and in control mice $(n=2)$. Error bars indicate SEM.

doubly, conditional mutant mice (Fig. 5A-D). Utrophin and $M u S K$ genes, like $A C h R$ genes, are expressed selectively by synaptic nuclei and respond to Nrg-1 in vitro, raising the possibility that synaptic expression of these genes may require Nrg-1. We therefore examined their expression pattern in mice lacking muscleand neuronally derived Nrg-1 and found that MuSK and Utrn mRNAs are patterned normally in HSA:: $\mathrm{cre}$; isl1 ${ }^{\mathrm{cre} /+} ; \mathrm{nrg}_{-} \mathrm{f}^{\mathrm{fl}-}$ embryos (Fig. $5 E-H$ ). These results indicate that the pattern of synapse-specific gene expression does not depend on expression of Nrg-1 by motor neurons or muscle fibers.

To determine whether Nrg-1 regulates the level of $A C h R$ or MuSK gene expression in muscle, we measured MuSK and AChR $\delta$ subunit mRNA levels in gastrocnemius muscles from E18.5 HSA::cre; isl1 ${ }^{\text {cre/+ }}$; $n r g-1^{f /-}$ embryos by quantitative RT-PCR (Fig. 5I) (see Materials and Methods). We found that MuSK and $A C h R \delta$ expression levels are similar in control and mutant mice 

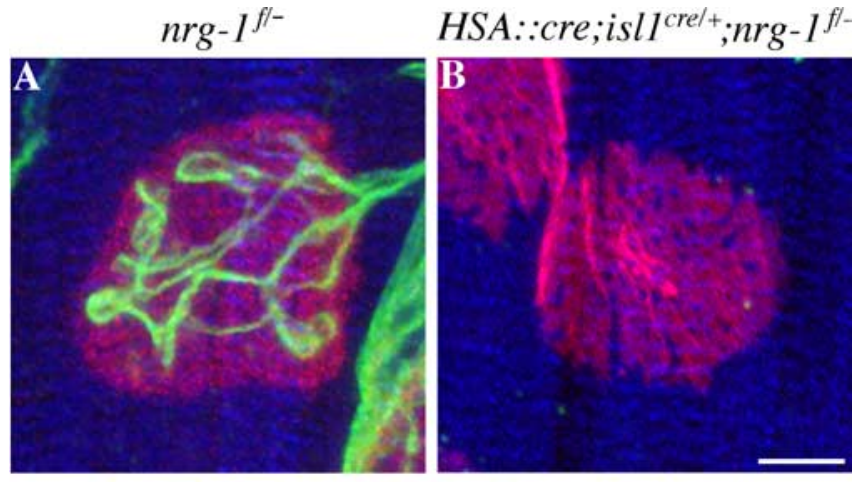

C
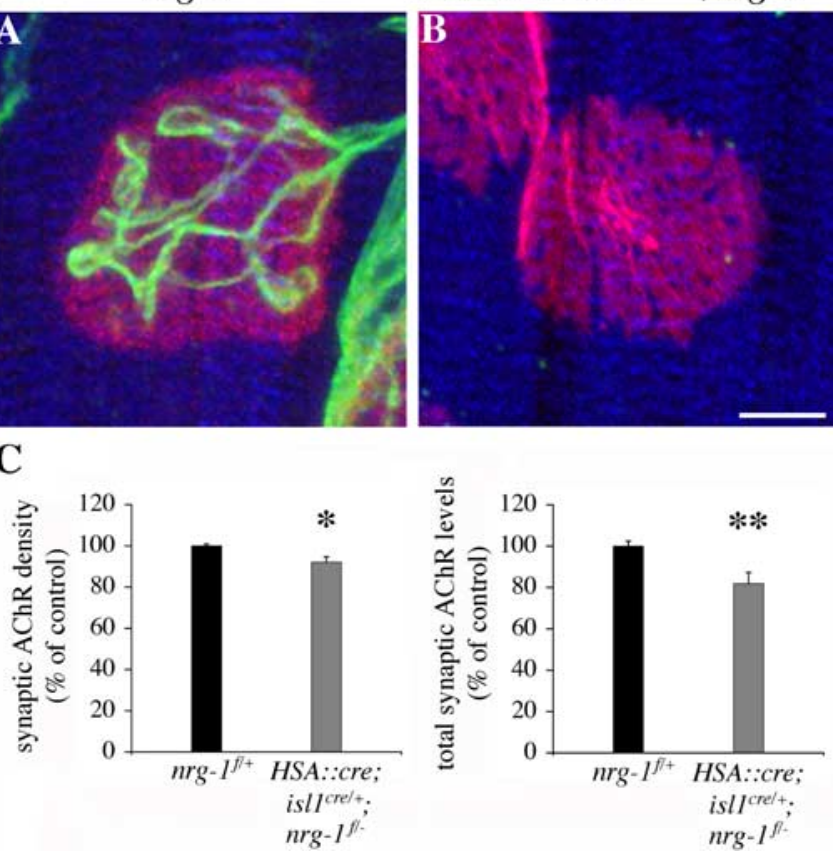

Figure 6. Synaptic AChR levels are reduced in mice lacking both neuronal- and musclederived Nrg-1. Whole mounts of diaphragm muscles from E18.5 embryos lacking neuronal and muscle-derived $\mathrm{Nrg}-1(\boldsymbol{B})$ and control embryos $(\boldsymbol{A})$ were stained as described in Figure 1. $\boldsymbol{A}$, In control mice, $A C h R s$ are apposed to nerve terminals. $\boldsymbol{B}$, In mice lacking neuronal- and musclederived Nrg-1, motor axons have withdrawn, but AChRs remain clustered at synaptic sites. $\boldsymbol{A}, \boldsymbol{B}$, $A C h R$ clusters appear morphologically similar in control mice and mice lacking Nrg-1 in neurons and muscle. Scale bar (in $\boldsymbol{B}) \boldsymbol{A}, \boldsymbol{B}, 5 \mu \mathrm{m}$. $\boldsymbol{C}$, The density and number of synaptic $A C h R s$ is reduced in mice lacking neuronal- and muscle-derived Nrg-1 $(n=8$ for doubly, conditional mutant mice; $n=7$ for control mice). Error bars indicate SEM. ${ }^{*} p<0.02$ and ${ }^{* *} p<0.01$ indicate that the values are significantly different from control.

(MuSK, $92 \pm 4.3 \%$ of control, $p>0.1 ; A C h R \delta, 103 \pm 7.1 \%$ of control, $p>0.5)$. Thus, the expression level of synapse-specific genes is not dependent on motor neuron- or muscle-derived Nrg-1.

We studied additional aspects of presynaptic and postsynaptic differentiation in whole-mount preparations of diaphragm muscles from HSA::cre; isl $1^{\text {cre/+ }}$; $n$ rg- $1^{f /-}$ embryos (Fig. 6). As expected for mice lacking neuronal Nrg-1, motor innervation is absent by E18.5 in embryos lacking both neuronal- and musclederived Nrg-1, because of the absence of Schwann cells, but AChRs remain clustered at synaptic sites, and the shape of AChR clusters in these mutant mice appears normal (Fig. 6A,B). We quantitated the number and density of synaptic AChRs in HSA::cre; isl1 ${ }^{\text {cre/+}} ;{\mathrm{nrg}-1^{f /-}}^{\text {embryos and found that the number }}$ but not the density of synaptic AChRs is modestly, but significantly, reduced $(\sim 20 \%)$ in both gastrocnemius and diaphragm muscles of mice lacking neuronal- and muscle-derived Nrg-1 (gastrocnemius: AChR number, $71 \pm 6.4 \%$ of control, $p<0.05$; AChR density, $98 \pm 5.8 \%$ of control, $p>0.5 ; n=3$ for control; $n=4$ for mutant; diaphragm: AChR number, $82 \pm 5.4 \%$ of control, $p<0.01$; AChR density, $92 \pm 2.5 \%$ of control, $p<0.02$; $n=7$ for control; $n=8$ for mutant) (Fig. 6C). Because the total number of synaptic AChRs is a reflection of AChR density and synaptic size, these data indicate that synaptic size is reduced in mice lacking both neuronal- and muscle-derived Nrg-1. Because the number and density of synaptic AChRs is normal in mice lacking either neuronal- (Fig. 1C) or muscle-derived (Fig. 3E) Nrg-1, these results indicate that neuronal and muscle-derived
Nrg-1 have a redundant, although modest, role in regulating AChR number at neuromuscular synapses.

\section{Discussion}

$A C h R$ genes are transcribed at a higher rate in synaptic than extrasynaptic nuclei of muscle fibers, and this expression pattern contributes to the accumulation of AChRs in the postsynaptic membrane. Prevailing views of neuromuscular synapse formation suggest that Nrg-1 is a key signal for synapse-specific gene expression (Falls et al., 1993; Sandrock et al., 1997; Buonanno and Fischbach, 2001; Schaeffer et al., 2001). We conditionally inactivated Nrg-1 in motor neurons and muscle fibers, the two cellular sources of Nrg-1 at the neuromuscular synapse, and found that the pattern of synapse-specific transcription and the expression level of synaptic genes are normal in these mutant embryos. In mice lacking muscle-derived Nrg-1, synapses develop and mature normally, assuming a pretzel-like shape, and contain normal levels of synaptic AChRs. In the absence of motor neuron- and muscle-derived Nrg-1, however, the total number of synaptic AChRs is modestly reduced, indicating that neuronal- and muscle-derived Nrg-1 have a redundant, although minor, role in regulating AChR expression. Our results therefore provide strong evidence against an essential role for Nrg-1 in neuromuscular synapse formation and synapse-specific transcription during development. In addition, our findings indicate that musclederived Nrg-1 is dispensable for synapse-specific transcription in postnatal mice. Because neuronal $n r g-1$ mutant mice die at birth, however, our experiments do not exclude the possibility that neuronal Nrg-1 has a role in synapse-specific transcription postnatally.

We used isl $1^{\text {cre }}$ mice to conditionally inactivate Nrg- 1 in motor and sensory neurons. Isl $1^{\text {cre/+}} ; n r g-1^{f /-}$ mice phenocopy mice lacking Nrg-1/ErbB signaling in Schwann cells (Riethmacher et al., 1997; Morris et al., 1999; Woldeyesus et al., 1999; Yang et al., 2001), indicating that neuronal Nrg-1 is efficiently deleted in motor and sensory neurons of these conditionally mutant mice. We used HSA::cre mice to inactivate Nrg-1 in skeletal myofibers and demonstrated that HSA::cre mediates efficient (>95\%) deletion of a loxP-flanked lac $Z$ expression cassette. Indeed, it is likely that inactivation is even more efficient, because some of the $\mathrm{X}$-gal stain in myofibers likely arises from $\beta$-gal expression in interstitial cells and diffusion of the $\mathrm{X}$-gal reaction product to nearby myofibers (Fig. 2C).

Previously, we showed that Nrg-2 can activate $A C h R$ gene expression in muscle cells expressing ErbB4 and ErbB2 (Rimer et al., 2004), and these data therefore raised the possibility that Nrg-2 might substitute for Nrg-1 in regulating AChR expression. Nrg-2, however, is expressed by motor neurons and terminal Schwann cells but not by muscle, yet $A C h R$ expression appears normal in neuronal $n r g-1$ mutant mice, which lack Schwann cells and ultimately motor neurons. Thus, these data are inconsistent with the idea that Nrg-2 substitutes for Nrg-1 during development and is responsible for the normal pattern and level of AChR expression in neuronal $\mathrm{nrg}-1$ mutant mice.

Consistent with our findings, synapse-specific gene expression appears normal in mice lacking Nrg-1 receptors, ErbB4 and ErbB2, in skeletal muscle (Escher et al., 2005). Because Agrin and MuSK, but not Nrg-1, are essential for synapse-specific transcription, our data support the idea that Agrin/MuSK signaling regulates synapse-specific transcription directly without requiring Nrg-1 signaling. 


\section{References}

Buonanno A, Fischbach GD (2001) Neuregulin and ErbB receptor signaling pathways in the nervous system. Curr Opin Neurobiol 11:287-296.

Burden SJ (2002) Building the vertebrate neuromuscular synapse. J Neurobiol 53:501-511.

Chu GC, Moscoso LM, Sliwkowski MX, Merlie JP (1995) Regulation of the acetylcholine receptor epsilon subunit gene by recombinant ARIA: an in vitro model for transynaptic gene regulation. Neuron 14:329-339.

Cohen I, Rimer M, Lomo T, McMahan UJ (1997) Agrin-induced postsynaptic-like apparatus in skeletal muscle fibers in vivo. Mol Cell Neurosci 9:237-253.

Corfas G, Rosen KM, Aratake H, Krauss R, Fischbach GD (1995) Differential expression of ARIA isoforms in the rat brain. Neuron 14:103-115.

DeChiara TM, Bowen DC, Valenzuela DM, Simmons MV, Poueymirou WT, Thomas S, Kinetz E, Compton DL, Rojas E, Park JS, Smith C, DiStefano PS, Glass DJ, Burden SJ, Yancopoulos GD (1996) The receptor tyrosine kinase MuSK is required for neuromuscular junction formation in vivo. Cell 85:501-512.

Escher P, Lacazette E, Courtet M, Blindenbacher A, Landmann L, Bezakova G, Lloyd KC, Mueller U, Brenner HR (2005) Synapses form in skeletal muscles lacking neuregulin receptors. Science 308:1920-1923.

Falls DL, Rosen KM, Corfas G, Lane WS, Fischbach GD (1993) ARIA, a protein that stimulates acetylcholine receptor synthesis, is a member of the neu ligand family. Cell 72:801-815.

Fromm L, Burden SJ (1998) Synapse-specific and neuregulin-induced transcription require an ets site that binds GABPalpha/GABPbeta. Genes Dev 12:3074-3083.

Gassmann M, Casagranda F, Orioli D, Simon H, Lai C, Klein R, Lemke G (1995) Aberrant neural and cardiac development in mice lacking the ErbB4 neuregulin receptor. Nature 378:390-394.

Gautam M, Noakes PG, Moscoso L, Rupp F, Scheller RH, Merlie JP, Sanes JR (1996) Defective neuromuscular synaptogenesis in agrin-deficient mutant mice. Cell 85:525-535.

Glass DJ, Bowen DC, Stitt TN, Radziejewski C, Bruno J, Ryan TE, Gies DR, Shah S, Mattsson K, Burden SJ, DiStefano PS, Valenzuela DM, DeChiara TM, Yancopoulos GD (1996) Agrin acts via a MuSK receptor complex. Cell 85:513-523.

Goodearl AD, Yee AG, Sandrock Jr AW, Corfas G, Fischbach GD (1995) ARIA is concentrated in the synaptic basal lamina of the developing chick neuromuscular junction. J Cell Biol 130:1423-1434.

Gramolini AO, Angus LM, Schaeffer L, Burton EA, Tinsley JM, Davies KE, Changeux JP, Jasmin BJ (1999) Induction of utrophin gene expression by heregulin in skeletal muscle cells: role of the N-box motif and GA binding protein. Proc Natl Acad Sci USA 96:3223-3227.

Gundersen K, Sanes JR, Merlie JP (1993) Neural regulation of muscle acetylcholine receptor epsilon- and alpha-subunit gene promoters in transgenic mice. J Cell Biol 123:1535-1544.

Herbst R, Avetisova E, Burden SJ (2002) Restoration of synapse formation in Musk mutant mice expressing a Musk/Trk chimeric receptor. Development 129:5449-5460.

Ip FC, Glass DG, Gies DR, Cheung J, Lai KO, Fu AK, Yancopoulos GD, Ip NY (2000) Cloning and characterization of muscle-specific kinase in chicken. Mol Cell Neurosci 16:661-673.

Jo SA, Zhu X, Marchionni MA, Burden SJ (1995) Neuregulins are concentrated at nerve-muscle synapses and activate ACh-receptor gene expression. Nature 373:158-161.

Jones G, Meier T, Lichtsteiner M, Witzemann V, Sakmann B, Brenner HR (1997) Induction by agrin of ectopic and functional postsynaptic-like membrane in innervated muscle. Proc Natl Acad Sci USA 94:2654-2659.

Jones G, Moore C, Hashemolhosseini S, Brenner HR (1999) Constitutively active MuSK is clustered in the absence of agrin and induces ectopic postsynaptic-like membranes in skeletal muscle fibers. J Neurosci 19:3376-3383.

Lacazette E, Le Calvez S, Gajendran N, Brenner HR (2003) A novel pathway for MuSK to induce key genes in neuromuscular synapse formation. J Cell Biol 161:727-736.

Lee KF, Simon H, Chen H, Bates B, Hung MC, Hauser C (1995) Require- ment for neuregulin receptor erbB2 in neural and cardiac development. Nature 378:394-398.

Lobe CG, Koop KE, Kreppner W, Lomeli H, Gertsenstein M, Nagy A (1999) $\mathrm{Z} / \mathrm{AP}$, a double reporter for cre-mediated recombination. Dev Biol 208:281-292.

Meier T, Masciulli F, Moore C, Schoumacher F, Eppenberger U, Denzer AJ, Jones G, Brenner HR (1998) Agrin can mediate acetylcholine receptor gene expression in muscle by aggregation of muscle-derived neuregulins. J Cell Biol 141:715-726.

Meyer D, Birchmeier C (1995) Multiple essential functions of neuregulin in development. Nature 378:386-390.

Miniou P, Tiziano D, Frugier T, Roblot N, Le Meur M, Melki J (1999) Gene targeting restricted to mouse striated muscle lineage. Nucleic Acids Res 27:e27.

Moore C, Leu M, Muller U, Brenner HR (2001) Induction of multiple signaling loops by MuSK during neuromuscular synapse formation. Proc Natl Acad Sci USA 98:14655-14660.

Morris JK, Lin W, Hauser C, Marchuk Y, Getman D, Lee KF (1999) Rescue of the cardiac defect in ErbB2 mutant mice reveals essential roles of ErbB2 in peripheral nervous system development. Neuron 23:273-283.

Moscoso LM, Chu GC, Gautam M, Noakes PG, Merlie JP, Sanes JR (1995) Synapse-associated expression of an acetylcholine receptor-inducing protein, ARIA/heregulin, and its putative receptors, ErbB2 and ErbB3, in developing mammalian muscle. Dev Biol 172:158-169.

Riethmacher D, Sonnenberg-Riethmacher E, Brinkmann V, Yamaai T, Lewin GR, Birchmeier C (1997) Severe neuropathies in mice with targeted mutations in the ErbB3 receptor. Nature 389:725-730.

Rimer M, Cohen I, Lomo T, Burden SJ, McMahan UJ (1998) Neuregulins and erbB receptors at neuromuscular junctions and at agrin-induced postsynaptic-like apparatus in skeletal muscle. Mol Cell Neurosci 12:1-15.

Rimer M, Prieto AL, Weber JL, Colasante C, Ponomareva O, Fromm L, Schwab MH, Lai C, Burden SJ (2004) Neuregulin-2 is synthesized by motor neurons and terminal Schwann cells and activates acetylcholine receptor transcription in muscle cells expressing ErbB4. Mol Cell Neurosci 26:271-281.

Sandrock Jr AW, Goodearl AD, Yin QW, Chang D, Fischbach GD (1995) ARIA is concentrated in nerve terminals at neuromuscular junctions and at other synapses. J Neurosci 15:6124-6136.

Sandrock Jr AW, Dryer SE, Rosen KM, Gozani SN, Kramer R, Theill LE, Fischbach GD (1997) Maintenance of acetylcholine receptor number by neuregulins at the neuromuscular junction in vivo. Science 276:599-603.

Sanes JR, Lichtman JW (2001) Induction, assembly, maturation and maintenance of a postsynaptic apparatus. Nat Rev Neurosci 2:791-805.

Schaeffer L, Duclert N, Huchet-Dymanus M, Changeux JP (1998) Implication of a multisubunit Ets-related transcription factor in synaptic expression of the nicotinic acetylcholine receptor. EMBO J 17:3078-3090.

Schaeffer L, de Kerchove d'Exaerde A, Changeux JP (2001) Targeting transcription to the neuromuscular synapse. Neuron 31:15-22.

Simon AM, Hoppe P, Burden SJ (1992) Spatial restriction of AChR gene expression to subsynaptic nuclei. Development 114:545-553.

Srinivas S, Watanabe T, Lin CS, William CM, Tanabe Y, Jessell TM, Costantini F (2001) Cre reporter strains produced by targeted insertion of EYFP and ECFP into the ROSA26 locus. BMC Dev Biol 1:4.

Tang J, Jo SA, Burden SJ (1994) Separate pathways for synapse-specific and electrical activity-dependent gene expression in skeletal muscle. Development 120:1799-1804.

Wilkinson DG (1998) In situ hybridization: a practical approach, Chap 4.4, Ed 2 (Wilkinson DG, ed), pp 89-99. New York: Oxford UP.

Woldeyesus MT, Britsch S, Riethmacher D, Xu L, Sonnenberg-Riethmacher E, Abou-Rebyeh F, Harvey R, Caroni P, Birchmeier C (1999) Peripheral nervous system defects in erbB2 mutants following genetic rescue of heart development. Genes Dev 13:2538-2548.

Yang X, Arber S, William C, Li L, Tanabe Y, Jessell TM, Birchmeier C, Burden SJ (2001) Patterning of muscle acetylcholine receptor gene expression in the absence of motor innervation. Neuron 30:399-410.

Zhu X, Lai C, Thomas S, Burden SJ (1995) Neuregulin receptors, erbB3 and erbB4, are localized at neuromuscular synapses. EMBO J 14:5842-5848. 